\title{
Prospects of Introduction of Fiber Lasers for Laser Heat Treatment of Ferrous Metals
}

\author{
Vladislav Somonov \\ Russian-German Center of Laser Technology of Saint-Petersburg State Polytechnical University, Russia \\ Email: ballak@inbox.ru
}

Received 25 August 2014; revised 2 October 2014; accepted 3 November 2014

Copyright (C) 2014 by author and OALib.

This work is licensed under the Creative Commons Attribution International License (CC BY). http://creativecommons.org/licenses/by/4.0/

(c) ()

\begin{abstract}
The article reflects the results of the study of the process of hardening of steels radiation fiber laser and the increase of productivity of process of laser hardening due to implementation of fiberoptic lasers instead of $\mathrm{CO}_{2}$ and the increase of the coefficient of absorption of laser radiation and the exclusion of the necessity to use absorbing coating. The research studied the structure of the hardened layer, compared with the structure of the obtained on $\mathrm{CO}_{2}$ laser, and presented practical results of hardening fiber laser.
\end{abstract}

Keywords

Fiber Laser, Laser Hardening, The Structure of the Hardened Layer

Subject Areas: Applied Physics, Electric Engineering

\section{Introduction}

Laser heat treatment is a method of local modification of the surface of metals. New laser sources (fiber lasers) are attracting more interest specialists. The emergence of fiber lasers has marked a breakthrough in laser physics; in a few years, their power output has been increased several times from hundreds of watts to tens of kilowatts. The fiber laser-a compact light source — has a feature of a long service life, reliability and ease in use. It occupies a large market share laser sources [1].

The main goal of laser thermal hardening alloys is to increase the wear resistance of the parts working in conditions of friction. Reduction of wear and tear occurs due to the high hardness and dispersion structure, increase of the load-bearing properties of the surface, etc. [2]. Laser hardening by analogy with other forms of hardening consists of information at the stage of heating austenitic structure and its subsequent transformation into martensite at the stage of cooling, but it has a number of advantages:

Without contact of the method of processing;

The possibility of local hardening of only the required places on the product; 
Lack of application of the cooling medium, in contrast to the hardening furnace or hardening of induction heating;

The total absence of residual deformation;

Flexibility and automation of the process.

In a series of problems of processes of hardening, one of the most actual is hardening without melting. For example, hardening of stamping equipment is inadmissible local melting of metal even in zonules (microareas) [3]. Comparison between several types of lasers used in laser hardening is as follows:

$\mathrm{CO}_{2}$-lasers are characterized by extremely low energy efficiency $\approx 10 \%$. The coefficient of absorption of metals radiation of the wave-length does not exceed a few percent, so that the full efficiency of the process of hardening is a fraction of a percent. Its increase is necessary to use different technologies of application of absorbing coatings based on oxides of $\mathrm{Al}$ and $\mathrm{Zn}, \mathrm{C}$ and other chemical compounds [4]. This greatly complicates the process and introduces him a lot of hard controlled factors.

YAG-laser absorption coefficient can reach $10 \%$ - 15\%, but the full efficiency of the laser is usually no more than $2 \%-3 \%$ [5].

The appearance of new powerful laser source fiber type, the efficiency of which is about $25 \%$, actualizes the issue of the efficiency of their use for laser hardening [6].

\section{Equipment and Materials}

The work was carried out on a laser technological complexes, available at the disposal of the laboratory of the Institute of laser and welding technologies (ILWT) and the Russian-German laser technology center of SaintPetersburg state Polytechnic University. As a source of laser radiation were used ytterbium fibre lasers LS-5 and LS-15 with a maximum power output of 5 and $15 \mathrm{~kW}$, the wave length of $1.07 \mu \mathrm{m}$. Radiation have been transported on the fiber cable to the optical laser head. To focus the radiation used head YW50 firm Precitec and HighYAG BIMO (Figure 1).

During the studies used samples made from steel grades:

St3, Steel 45, 65Г, 38X2H2MA, 40S, 30X13 thickness from 2 to $40 \mathrm{~mm}$.

Processing was carried out straight individual parcels. Everywhere laser was used in the mode of continuous radiation. Mode settings ranged such a way that the energy density of the tempering, calculated as a ratio of the laser radiation power to the product of the width of the hardened layer and the speed of hardening, has changed from 1.75 to $6.4 \mathrm{~J} / \mathrm{mm}^{2}$. For comparison, from the literary data [4] when processed by $\mathrm{CO}_{2}$ laser requires a higher specific energy tempering from 13.3 to $33.1 \mathrm{~J} / \mathrm{mm}^{2}$. Metallographic sections were made from the processed samples that have passed visual control for the absence of melting or cracking of the surface. Were determined structural components, the width and depth of the hardened layer using the photos of metallographic sections. Measurements of microhardness of hardened layer, the transition layer and the area of the base metal were made using the microhardness-testing machine PMT-3 (Figure 2).

\section{The Results of Experiments}

The depth of the resulting hardened layer ranged from 100 to 300 microns. The increase in microhardness ranged from 1.2 to 1.7 times. The speed of hardening came up to $3 \mathrm{~m} / \mathrm{min}$. This became possible due to more efficient absorption rate in fiber lasers, than that of $\mathrm{CO}_{2}$. When hardening by fiber lasers there is no need to apply absorbing coatings, this further reduces the value of the process and makes it environmentally friendly. It was noted that the microstructure of hardened layer, carried out on the ЛС-5 is rather homogeneous, has the form of the fine-dispersed martensite and it completely missing the transition zone, while in the processing of the $\mathrm{CO}_{2}-$ laser according to the literary data [3] [5] in the structure of the present transition zone. The measured values of microhardness of the hardened layer were somewhat higher than those obtained by quenching $\mathrm{CO}_{2}$ laser. The values of microhardness and a photo of the structure of the hardened layer of steel grade 38X2H2MA are shown in Figure 3.

Examples of products, tempered by fiber-optic laser are presented in Figure 4.

\section{Conclusion}

Testing of the process of hardening of metals' radiation fiber laser shows that the overall efficiency of the process (as a ratio of performance to spent radiation power) even without the use of absorbing coatings 

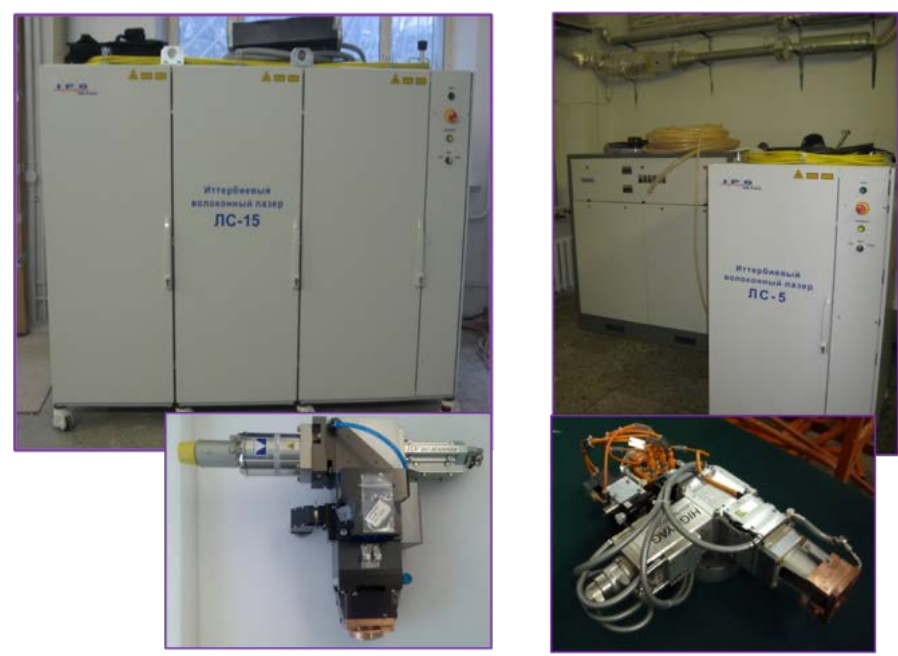

Figure 1. The image of the lasers LS-15 and LS-5, laser heads YW50 and HighYAG BIMO.

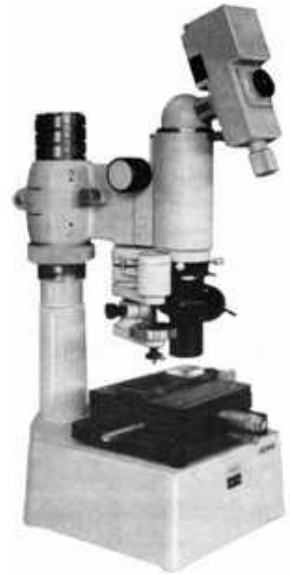

Figure 2. The image of the microhardness-testing machine PMT-3.

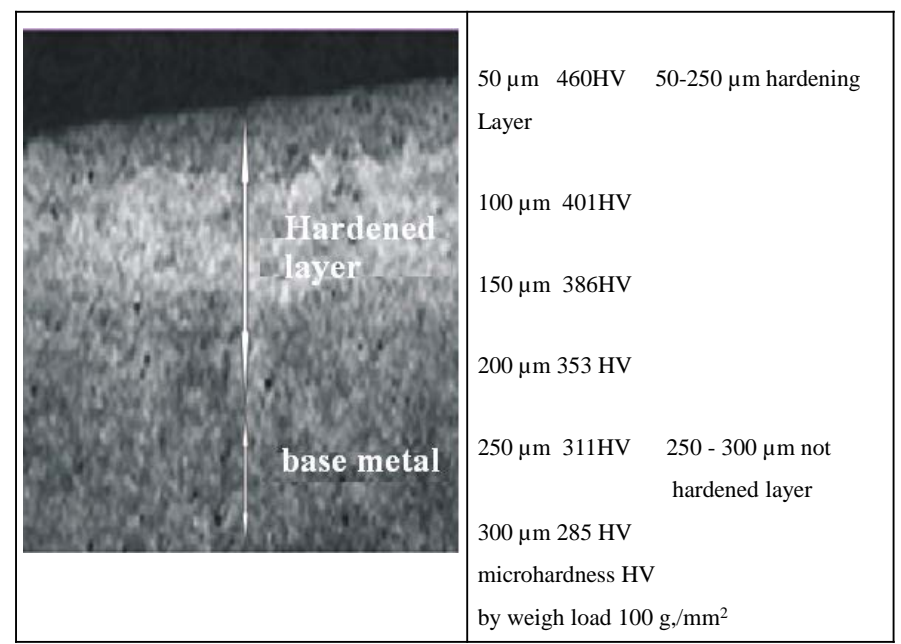

Figure 3. The image of the structure of hardened layer of steel grade $38 \mathrm{X} 2 \mathrm{H} 2 \mathrm{MA}$, obtained in the processing of the fibers Yb laser LS-5 and the measured values of microhardness. 

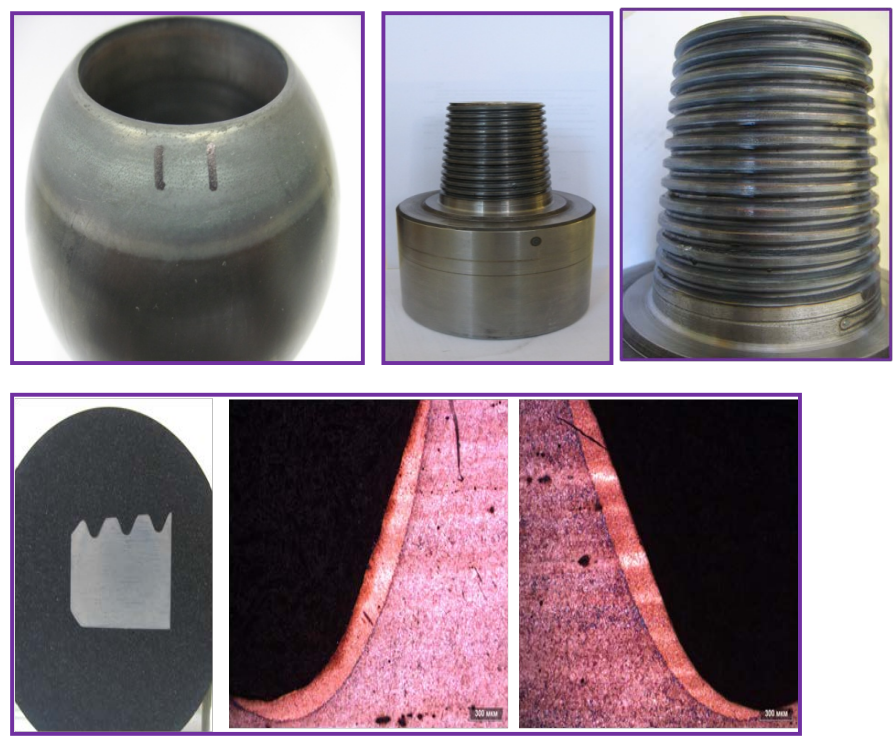

Figure 4. The image of hardened products.

in several times exceeds the values of the effectiveness of the process for $\mathrm{CO}_{2}$-lasers that are listed in the literary data [3] [5]. The use of laser hardening allows achieving the steel surface hardness, while maintaining sufficient viscosity core. The structure of the hardened layer of homogeneous has the form of the fine-dispersed martensite and is completely missing from the transition zone. Taking into account that the required energy density hardening to the process of hardening by fiber lasers in comparison with $\mathrm{CO}_{2}$ less in a few times, his business competitiveness can be concluded. The delivery of radiation on optical fiber excludes application of absorbing coatings. This process is environmentally, friendly and fully controlled.

\section{References}

[1] Markin, E.P., Losovoyi, A.K., Smirnov, S.N. and Yahontov, U.G. (2011) Experience of Industrial Application of Laser Processing Systems Based on Fiber Generators. Proceedings of the Universities. Laser Treatment, 2.

[2] Veselovsky, V.B. and Gubin, A.I. (2008) Mathematical Modeling of Laser Thermal Hardening without Melting the Surface of. Metallurgical Heat Engineering Collection of Scientific Works.

[3] Popov, V. (2009) Laser Hardening Steels: Comparison of Fibre and $\mathrm{CO}_{2}$ Lasers. Photonics, 4.

[4] Grigor'yanz, A.G., Shiganov, I.N. and Mis’urov, A.I. (2006) Technological Processes of Laser Processing, MGTU. AD. Bauman.

[5] Scripchenco, A.I., Medvedski, V.M. and Popov, V. (2007) Thus the Steel Was Tempered or Testing of the Process of Hardening of Steels Radiation Fiber Lasers. RITM, 29.

[6] Cymbals, A.L. (2010) Laser Hardening of Steel. St. Petersburg State University, ITMO. 